\title{
PREVALENCE OF RESPIRATORY SYMPTOMS AND PULMONARY FUNCTION STATUS OF RESTAURANT WORKERS
}

\author{
Mohammed Abdulrazzaq Jabbar ${ }^{1}$, Retneswari Masilamani ${ }^{1}$, Lim Zhi Yik ${ }^{1}$, Chen Pei Fei ${ }^{1}$, Loh Xin $\mathrm{Ni}^{1}$, \\ Emilia Chua Pei $\mathrm{Yi}^{1}$, Loh Yen Yee ${ }^{1}$ and Wisam A Yassin ${ }^{1}$

\begin{abstract}
${ }^{1}$ Mohammed Abdulrazzaq Jabbar. Faculty of Medicine and Health Sciences. Universiti Tunku Abdul Rahman. 43000 Kajang. Malaysia.

${ }^{1}$ Retneswari Masilamani. Faculty of Medicine and Health Sciences. Universiti Tunku Abdul Rahman. 43000 Kajang. Malaysia.

${ }^{1}$ Lim Zhi Yik. Faculty of Medicine and Health Sciences. Universiti Tunku Abdul Rahman. 43000 Kajang. Malaysia.

${ }^{1}$ Chen Pei Fei. Faculty of Medicine and Health Sciences. Universiti Tunku Abdul Rahman. 43000 Kajang. Malaysia.

${ }^{1}$ Loh Xin Ni. Faculty of Medicine and Health Sciences. Universiti Tunku Abdul Rahman. 43000 Kajang. Malaysia.

${ }^{1}$ Emilia Chua Pei Yi. Faculty of Medicine and Health Sciences. Universiti Tunku Abdul Rahman. 43000 Kajang. Malaysia.

${ }^{1}$ Loh Yen Yee. Faculty of Medicine and Health Sciences. Universiti Tunku Abdul Rahman. 43000 Kajang. Malaysia.
\end{abstract} \\ ${ }^{1}$ Wisam A Yassin. Faculty of Medicine and Health Sciences. Universiti Tunku Abdul Rahman. 43000 Kajang. Malaysia
}

Corresponding author: Mohammed Abdulrazzaq Jabbar

Email: jabbar@utar.edu.my

\section{ABSTRACT}

The cooking process may emit toxic compounds and airway irritants from both the fuel combustion and cooking fumes which is harmful to the respiratory health among the restaurant workers. A cross-sectional study of 243 restaurant workers from the selected restaurants in Sungai Long, Malaysia was conducted. The standardized British Medical Research Council questionnaire on Respiratory Symptoms (1986) was used during the interview to access the symptoms and the spirometry test was performed to evaluate the pulmonary functions of the participants. The data of sociodemography and occupational characteristics were also collected. The most complaint respiratory symptoms by the restaurant workers were breathlessness, which accounted for $33.7 \%$, followed by wheezing (14\%). The mean values of all pulmonary function tests (PFT) of the restaurant workers were within the normal range (>80\%), except for the Peak Expiratory Flow (PEF) (79.09\%). The results of the bivariate statistical analysis, Chi-square, ANOVA and t-test, showed the determining factors of the respiratory health among the workers were workers' age and gender in addition to the working duration and the ethnicity. The restaurant workers in Sungai Long were at risk of developing respiratory symptoms and lower pulmonary function values due to prolonged exposure to cooking fumes. Emphasis should be given to the safety and health of restaurant workers and health education should be provided to the restaurant workers and owners. Strategies to increase notification of such occurrences among these workers should be looked into by related agencies in the country.

Key words: Respiratory Symptoms, Pulmonary Function Test, Restaurants Workers

\section{INTRODUCTION}

Some 3 million deaths a year linked to exposure to outdoor air pollution and indoor air pollution can be just as deadly. In 2012, an estimated 6.5 million deaths $(11.6 \%$ of all global deaths) were associated with indoor and outdoor air pollution together ${ }^{1}$. At present, most people are tied up with a fast-paced lifestyle due to rapid urbanization, leaving no time to prepare home-cooked food leisurely. This has given rise to dining in restaurants and food delivery services, catering to people who are too tired and busy to prepare their food at home. Higher demand to outside meals, therefore, set a growth rate in Malaysia's Food and Beverages industry. This, however, had a negative impact on preserving the health of restaurant workers as they are unavoidably exposed to respiratory hazards from cooking fumes for a long duration. Cooking oil fumes contain a mixture of various complex compounds, and these compounds vary depending on the type of cooking practices, such as grilling, boiling, stirfrying, deep-frying etc, and the type of ingredients or oil used for cooking as well as the presence of adequate ventilators to extract fumes in the cooking environment. It was found that some of the toxic compounds in cooking oil fumes are carcinogenic due to its ability to induce genetic mutation, for instance, polycyclic aromatic hydrocarbons (PAHs), formaldehyde, benzene, and heterocyclic aromatic amines which can cause oxidative DNA damage, associated with lung malignancies among non-smoking restaurant workers ${ }^{2}$. Furthermore, particulate matter (PM), carbon monoxide $(\mathrm{CO})$ and nitrogen dioxide $\left(\mathrm{NO}_{2}\right)$ from fuel combustion may be associated with respiratory symptoms such as asthma ${ }^{3}$. 
After realizing the adverse effect of cooking smoke, the Malaysian government sector has started to pay attention to restaurant workers who are constantly exposed to cooking smoking in their cooking environment, therefore, Department of Occupational Safety and Health (DOSH) issued the Industry Code of Practice on Indoor Air Quality 2010 (ICOP IAQ 2010) to ensure restaurant workers are kept safe from poor indoor air quality ${ }^{4}$. Nevertheless, with existing studies showing that kitchen workers have an increased occurrence of respiratory symptoms, doubtlessly restaurant workers are more prone to developing respiratory symptoms which may lead to lung diseases compared to other populations. However, scanty evidence of literature in Malaysia allowed agreement with these studies although the number of cases of occupational lung diseases reported in 2018 was the 4th highest among all occupational diseases, according to the Ministry of Human Resources of Malaysia ${ }^{5}$.

Therefore, this study was aimed to determine the prevalence of respiratory symptoms and pulmonary function status of restaurant workers in Malaysia so that relative safety measures can be implemented to protect restaurant workers with limited knowledge on occupational risks they are exposed to. Sociodemographic factors and occupational characteristics were also taken into consideration as possible risk factors of respiratory symptoms, including reduced pulmonary function among restaurant workers, to study their respective association with each other.

\section{METHODOLOGY}

This cross-sectional study was carried out at Sungai Long, located in Kajang of Selangor with a $2.79 \mathrm{~km}^{2}$ total area ${ }^{6}$. This township is 40 minutes' drive away from Kuala Lumpur, the capital city of Malaysia. Restaurant workers in Sungai Long, Malaysia, comprised of locals and foreigners were recruited as subjects of this study. A Brief surveillance of the total number of restaurants and the corresponding number of restaurant workers was conducted before the sample collection. There are 70 restaurants with a total of 645 restaurant workers in Sungai Long Town. Two stages of sampling methods were conducted in August 2019. In the first stage, randomisation of the restaurant was done and 35 restaurants were chosen. Subsequently, a universal sampling was conducted on all 35 chosen restaurants to fulfil our calculated sampling size of 276 subjects. A response rate of $88 \%$ was achieved by 243 eligible participants recruited, with informed consent, into this study.

The data collection was carried out by interview sessions in four parts comprising of socio- demographic background, occupational characteristics, presence of respiratory symptoms (cough, phlegm, wheeze, breathlessness and chest illness) and the assessment of pulmonary function of the workers. The occupational characteristics included working period, working duration, job scope and the type of restaurants studied. The working period was defined as years of working experience in the food and beverage industry while working duration represented the time (hours) that the workers had to work per week. The type of restaurants were classified into three groups: "Casual dining" which serves moderately-priced food or traditional breakfast, typically with shared kitchen, "Café" - a small and informal establishment which mainly serves refreshments and "Others" included Mamak restaurants (restaurant typically found in Malaysia and Singapore, run by southern Indian-Muslim), fast food and buffet.

The respiratory symptoms of every restaurant worker were evaluated by using a questionnaire on Respiratory Symptoms ${ }^{7}$, adopted from the British Medical Research Council by five well-trained interviewers. The interview was carried out by using local Malaysian Language (Bahasa Malaysia) and all the respondents were speaking the local language including the foreign workers. The assessment of pulmonary function [forced expiratory volume at 1 second $\left(\mathrm{FEV}_{1}\right)$, forced vital capacity (FVC), the ratio of $\mathrm{FEV}_{1}$ to $\mathrm{FVC}$ in addition to peak expiratory flowrate (PEF)] was done by using calibrated spirometer (Spirobank II, MIR) ${ }^{8}$ and peak flow meter (Peak flow meter MINI-WRIGHT STANDARD, Clement Clarke International) ${ }^{9}$. The collected data were analysed by using SPSS version 22 and the prevalence of respiratory symptoms was obtained by descriptive analysis. The research was approved by the Scientific and Ethical Review Committee in Universiti Tunku Abdul Rahman number U/SERC/122/2019 on August 5th, 2019.

\section{RESULTS}

Workers' health and demographic characteristics The most common respiratory symptom complained by restaurant workers in our study was breathlessness (33.7\%). Only a few of them complained of cough $(5.8 \%)$, phlegm $(9.5 \%)$, wheezing (14.0\%) and chest illness (10.3\%). The pulmonary function tests consisted of FEV1 (\%), FVC (\%), $\mathrm{FEV}_{1} / \mathrm{FVC}$ ratio and PEFR (\%). The mean percentage of $\mathrm{FEV}_{1}$ of the participants was 82.44 (sd $=19.15)$ while FVC was 80.07 (sd = 18.21). The $\mathrm{FEV}_{1} / \mathrm{FVC}$ ratio (\%) was averagely high with a mean of 89.42 ( $s d=12.49$ ). PEFR had a mean percentage of 79.09 (sd = 18.27). The mean age of the participants was 33.06 years old $(s d=12.41)$. The study participants consisted of 138 males (56.8\%) 
and 105 females (43.2\%), of whom 114 were Chinese (46.9\%), 39 were Malay (16.0\%), 12 were Indian $(4.9 \%)$ and 78 were other races $(32.1 \%)$. The other ethnicities included Javanese, Bamar, Bengali, Siamese and Tagalog. Out of 243 participants, 144 of them were Malaysian (59.3\%) while 99 of them were non-Malaysian (40.7\%). Non-Malaysian included was Indonesian, Myanmar, Bangladeshis and South Indian. About half of them never smoke before (59.3\%). The average working duration of the participants was 59.31 months $(s d=20.29)$ and 209 of them $(86.0 \%)$ had worked in restaurants for less than 10 years while only 34 of them worked in restaurants for more than 10 years. In our study interpretation, we further categorized the job scope into 3 components including chef, waiter, and others (admin, barista, cleaner and rider). Majority of them were chef $(43.2 \%)$ followed by waiters $(32.5 \%)$ and admin $(13.2 \%)$. The types of the restaurant were categorized into 3 groups based on their cooking methods including casual dining (casual dining and traditional breakfast shop), café and others (Mamak, fast food and buffet). Most of the participants (36.6\%) from traditional breakfast shop followed by casual dining (32.9\%). Table 1 summarizes the characteristics of the study participants.

\section{Selected risk factors for most significant respiratory symptoms}

The gender was not associated with any symptoms. The other ethnicities including Javanese, Bamar, Bengali, Siamese and Tagalog reported having a higher prevalence of cough and wheezing than Chinese, Malay and Indian; statistical significance $(p=0.001 ; p=0.006)$. Chinese ethnicity reported the highest prevalence of breathlessness, but it was not significantly associated $(p>0.05)$. Non-Malaysian restaurant workers including Indonesian, Burmese, Bangladeshis and South Indian reported a higher prevalence of cough and wheezing than Malaysian restaurant workers; statistical significance $(p<0.001 ; p=0.021)$. Breathlessness was more common among Malaysians, but this association was not statistically significant $(p>0.05)$. The mean working duration of restaurant workers who reported cough symptom (66.50) was higher than the mean working duration of restaurant workers who did not report cough symptom (58.87); the mean difference was statistically significant $(p=0.003)$. However, the working period and job scope were not associated with any symptoms. Type of restaurant was significantly associated with respiratory symptom breathlessness only $(p=0.030)$. Restaurant workers who worked in casual dining type of restaurant reported a higher prevalence of breathlessness than restaurant workers who worked in other types of restaurant. Table 2 shows the relationship between the most significant respiratory symptoms and selected risk factors.

\section{Selected risk factors and pulmonary function tests}

The mean $\mathrm{FEV}_{1}$ (\%) and PEFR value of female restaurant workers (79.27) were lower than the mean $\mathrm{FEV}_{1}(\%)$ of male restaurant workers (84.86). The mean difference was statistically significant $(p=0.02 ; p<0.001)$. Indian ethnicity reported a lower mean of $\mathrm{FEV}_{1}$ and FVC (\%). The mean difference was statistically significant $(p<0.001 ; p<0.001)$. Post hoc test (Turkey's HSD) revealed that the Indian restaurant workers had the lowest mean of $\mathrm{FEV}_{1}$ and FVC (\%) and the Chinese restaurant workers had the highest mean of FEV 1 and FVC (\%) which marked the significant difference. It was found that the mean PEFR value of other ethnicities was lower than the local ethnicity and the mean difference was statistically significant $(p<0.001)$. Post hoc test (Turkey's HSD) revealed that restaurant workers of other ethnicity had the lowest mean of PEF (\%) and the Chinese restaurant workers had the highest mean of PEF (\%) which marked the significant difference.

Local restaurant workers were having a higher mean of $\mathrm{FEV}_{1}$, and FVC, PEFR value than non-Malaysian restaurant workers. Hence, nationality was significantly associated with $\mathrm{FEV}_{1}, \mathrm{FVC}$ and PEFR $(p<0.001 ; p=0.006 ; p<0.001)$. There was a negative correlation between working duration (hours per week) and PEFR $(r=-0.133)$. The correlation was statistically significant $(p=0.03)$, though, the working period and job scope were not significantly associated with any of the symptoms. Lastly, the mean FVC of restaurant workers in other types of the restaurant was lower as compared to restaurant workers in casual dining restaurants and café. The mean difference was statistically significant $(p=0.021)$. Post hoc test (Turkey's HSD) revealed that restaurant workers in other types of the restaurant had the lowest mean FVC (\%) and the restaurant workers in cafe had the highest mean FVC (\%) which marked the significant difference. Table 3 illustrates the relationship between pulmonary function tests and selected risk factors. 
Table 1: Characteristics of the study participants

\begin{tabular}{|c|c|c|c|}
\hline Workers' Characteristics & $\mathrm{N}(\%)$ & m (sd) & $95 \% \mathrm{Cl}$ \\
\hline \multicolumn{4}{|l|}{ Respiratory Symptoms } \\
\hline Cough & $14(5.8)$ & & $3.3-9.1$ \\
\hline Phlegm & $23(9.5)$ & & $5.8-13.2$ \\
\hline Breathlessness & $82(33.7)$ & & $27.6-39.9$ \\
\hline Wheezing & $34(14.0)$ & & $9.5-18.1$ \\
\hline Chest Illness & $25(10.3)$ & & $6.6-14.4$ \\
\hline \multicolumn{4}{|c|}{ Pulmonary function to the predicted value } \\
\hline $\mathrm{FEV}_{1}$ & & $82.44(19.15)$ & $79.83-84.90$ \\
\hline FVC & & 80.07 (18.21) & $77.77-82.38$ \\
\hline $\mathrm{FEV}_{1} / \mathrm{FVC}$ & & 89.42 (12.49) & $87.68-90.93$ \\
\hline PEFR (\%) & & 79.09 (18.27) & $76.60-81.48$ \\
\hline \multicolumn{4}{|c|}{ Socio-demographic Characteristics } \\
\hline Age & & $33.06(12.41)$ & $31.49-34.57$ \\
\hline \multicolumn{4}{|l|}{ Gender } \\
\hline Male & $138(56.8)$ & & $50.6-63.4$ \\
\hline Female & $105(43.2)$ & & $36.6=49.4$ \\
\hline \multicolumn{4}{|l|}{ Ethnicity } \\
\hline Chinese & $114(46.9)$ & & $40.3-53.1$ \\
\hline Malay & $39(16.0)$ & & $11.5-20.6$ \\
\hline Indian & $12(4.9)$ & & $2.5-7.8$ \\
\hline Others* & $78(32.1)$ & & $26.3-38.3$ \\
\hline \multicolumn{4}{|l|}{ Nationality } \\
\hline Malaysian & $144(59.3)$ & & $52.3-65.4$ \\
\hline Non-Malaysian** & $99(40.7)$ & & $34.6-47.7$ \\
\hline \multicolumn{4}{|l|}{ Smoking } \\
\hline Currently & $70(30)$ & & $24.3-35.8$ \\
\hline Never & $144(59.3)$ & & $53.5-65.4$ \\
\hline Ex-smokers & $26(10.7)$ & & $7.0-14.4$ \\
\hline \multicolumn{4}{|l|}{ Occupational Characteristics } \\
\hline Working Duration (hr/wk) & & $59.31(20.29)$ & $56.78-62.05$ \\
\hline \multicolumn{4}{|l|}{ Working Period } \\
\hline$\leq 10$ years & $209(86)$ & & $81.5-90.5$ \\
\hline$>10$ years & $34(14)$ & & $9.5-18.5$ \\
\hline \multicolumn{4}{|l|}{ Job Scope } \\
\hline Chef & $105(43.2)$ & & $37.0-49.0$ \\
\hline Waiter & 79 (32.5) & & $26.7-39.1$ \\
\hline Admin & $32(13.2)$ & & $9.1-17.7$ \\
\hline Cleaner & $3(1.2)$ & & $0.0-2.9$ \\
\hline Barista & $21(8.6)$ & & $5.3-12.3$ \\
\hline Rider & $3(1.2)$ & & $0.0-2.9$ \\
\hline \multicolumn{4}{|l|}{ Type of Restaurant } \\
\hline Casual Dining & $80(32.9)$ & & $27.2-39.1$ \\
\hline Traditional Breakfast & 89 (36.6) & & $30.9-42.8$ \\
\hline Mamak & $13(5.3)$ & & $2.5-8.6$ \\
\hline Cafe & $38(15.6)$ & & $11.1-19.8$ \\
\hline Buffet & $5(2.1)$ & & $0.4-4.1$ \\
\hline Fast Food & $18(7.41)$ & & 4.110 .7 \\
\hline
\end{tabular}

Quantitative data are shown as mean \pm sd; categorical data are shown in number (percentage), *Ethnicity including Javanese, Bamar, Bengali, Siamese and Tagalog, ${ }^{* *}$ Non-Malaysian including Indonesian, Burmese, Bangladeshis and South Indian

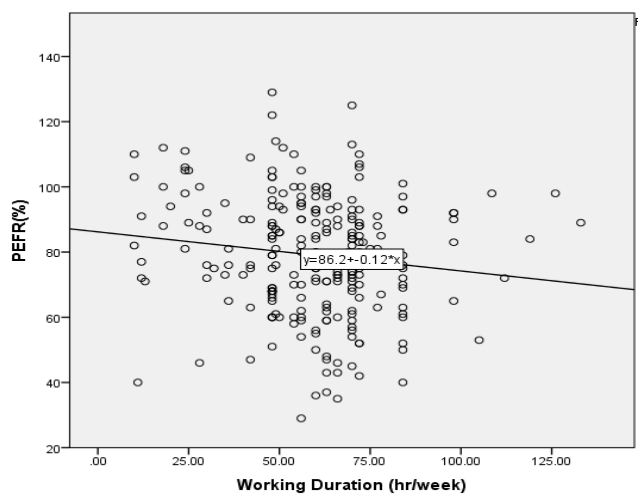

Graph 1: Graph of correlation between PEFR - Predicted and working duration (hr/wk) 
Table 2: The relationship between most significant respiratory symptoms and selected risk factors

\begin{tabular}{|c|c|c|c|c|c|c|}
\hline \multirow[b]{2}{*}{$\begin{array}{l}\text { Selected } \\
\text { Factors }\end{array}$} & \multicolumn{2}{|l|}{ Cough } & \multicolumn{2}{|c|}{ Breathlessness } & \multicolumn{2}{|l|}{ Wheezing } \\
\hline & $\begin{array}{l}\text { Yes } \\
\mathrm{N} \text { (\%) / m } \\
\text { (sd) }\end{array}$ & $\begin{array}{l}\text { No } \\
\mathrm{N} \text { (\%) / m } \\
\text { (sd) }\end{array}$ & $\begin{array}{l}\text { Yes } \\
N \text { (\%) / m } \\
\text { (sd) }\end{array}$ & $\begin{array}{l}\text { No } \\
N \text { (\%) / m } \\
\text { (sd) }\end{array}$ & $\begin{array}{l}\text { Yes } \\
\mathrm{N} \text { (\%) / m } \\
\text { (sd) }\end{array}$ & $\begin{array}{l}\text { No } \\
\text { N (\%) / m (sd) }\end{array}$ \\
\hline \multicolumn{7}{|l|}{ Gender A } \\
\hline Male & $8(5.8)$ & $130(94.2)$ & $43(31.2)$ & $95(68.8)$ & 22 (15.9) & $116(84.1)$ \\
\hline Female & $6(5.7)$ & $99(94.3)$ & $39(37.1)$ & $66(62.9)$ & $12(11.4)$ & $93(88.6)$ \\
\hline$x 2$, p-value & $0.001,0.97$ & & $0.95,0.32$ & & $1.00,0.31$ & \\
\hline \multicolumn{7}{|l|}{ Ethnicity A } \\
\hline Chinese & $1(0.9)$ & 113 (99.1) & $38(33.3)$ & 76 (66.7) & 9 (7.9) & 105 (92.1) \\
\hline Malay & $1(2.6)$ & $38(97.4)$ & $12(30.8)$ & $27(69.2)$ & $6(15.4)$ & $33(84.6)$ \\
\hline Indian & $1(8.3)$ & $11(91.7)$ & $3(25.0)$ & $9(75.0)$ & $0(0.0)$ & $12(100.0)$ \\
\hline Others & $11(14.1)$ & 67 (85.9) & $29(37.2)$ & $49(62.8)$ & $19(24.4)$ & $59(75.6)$ \\
\hline x 2, p-value & \multicolumn{2}{|c|}{$15.88,0.001^{*}$} & \multicolumn{2}{|l|}{$0.98,0.80$} & \multicolumn{2}{|c|}{$12.50,0.006^{*}$} \\
\hline \multicolumn{7}{|l|}{ Nationality A } \\
\hline Malaysian & $2(1.4)$ & $142(98.6)$ & 47 (32.6) & $97(67.4)$ & $14(9.7)$ & $130(90.3)$ \\
\hline Non-Malaysian & $12(12.1)$ & 87 (87.9) & $35(35.4)$ & $64(64.6)$ & $20(20.2)$ & 79 (79.8) \\
\hline x 2, p-value & \multirow{2}{*}{\multicolumn{2}{|c|}{$12.44,<0.001^{*}$}} & \multirow{2}{*}{\multicolumn{2}{|c|}{$0.19,0.66$}} & \multirow{2}{*}{\multicolumn{2}{|c|}{$5.35,0.021^{*}$}} \\
\hline Working Duration & & & & & & \\
\hline $\begin{array}{l}\text { (hr/wk) B } \\
\text { m (sd) }\end{array}$ & $66.50 \pm 7.01$ & $58.87 \pm 20.76$ & $59.30 \pm 20.36$ & $59.31 \pm 20.32$ & $63.12 \pm 19.59$ & $58.69 \pm 20.38$ \\
\hline$t, p$-value & $3.28,0.003^{*}$ & & $0.001,0.99$ & & $1.18,0.23$ & \\
\hline \multicolumn{7}{|l|}{ Working Period A } \\
\hline$\leq 10$ years & $11(5.3)$ & $198(94.7)$ & $66(31.6)$ & $143(68.4)$ & $30(14.4)$ & 179 (85.6) \\
\hline$>10$ years & $3(8.8)$ & $31(91.2)$ & $16(47.1)$ & $18(52.9)$ & $4(11.8)$ & $30(88.2)$ \\
\hline x 2, p-value & $0.68,0.42$ & & $3.13,0.08$ & & $0.16,1.00$ & \\
\hline \multicolumn{7}{|l|}{ Job Scope A } \\
\hline Chef & $4(3.8)$ & $101(96.2)$ & $40(38.1)$ & $65(61.9)$ & $19(18.1)$ & $86(81.9)$ \\
\hline Waiter & $8(10.1)$ & 71 (89.9) & $26(32.9)$ & $53(67.1)$ & $11(13.9)$ & $68(86.1)$ \\
\hline Othersm & $2(3.4)$ & 57 (96.6) & $16(27.1)$ & 43 (72.9) & $4(6.8)$ & $55(93.2)$ \\
\hline x 2, p-value & $4.07,0.13$ & & $2.07,0.35$ & & $4.02,0.13$ & \\
\hline \multicolumn{7}{|l|}{ Types of } \\
\hline \multirow{4}{*}{$\begin{array}{l}\text { Restaurant A } \\
\text { Casual dining } \\
\text { Cafe } \\
\text { Othersmm } \\
\times 2 \text {, p-value }\end{array}$} & $13(7.7)$ & $156(92.3)$ & $66(39.1)$ & 103 (60.9) & $28(16.6)$ & $141(83.4)$ \\
\hline & $0(0.0)$ & $38(100.0)$ & $8(21.1)$ & 30 (78.9) & $1(2.6)$ & 37 (97.4) \\
\hline & $1(2.8)$ & $35(97.2)$ & $8(22.2)$ & $28(77.8)$ & $5(13.9)$ & $31(86.1)$ \\
\hline & \multicolumn{2}{|l|}{$4.074,0.130$} & \multicolumn{2}{|l|}{$7.00,0.03^{*}$} & \multicolumn{2}{|l|}{$5.00,0.08$} \\
\hline
\end{tabular}

$\pi$ job scope others = Admin, Cleaner, Barista or Rider, $\pi \pi$ Types of restaurants others = Mamak, Café, Buffet or Fast Food, A Chi-square test, $B$ independent samples $t$ test

The predictors of the common respiratory symptoms among the restaurant workers

Table 4 shows the results of the binary logistic regression analysis to determine the predictors of the common respiratory symptoms among the study participants. The predictors involved in the model were Age (continuous data), Gender (female as reference group), smoking (nonsmokers the reference group), nationality (Malaysian nationality is reference group) and working duration $(<=10$ years as reference group).
The results for chronic cough revealed the Odd Ratio for Age, Gender, smoking, nationality and working duration were 1.04, 1.72, 0.30, 12.21 and 0.20 respectively. For breathlessness the Odd ratio for Age, gender, smoking, nationality and working duration were $0.98,1.60,0.55,1.16$ and 0.60 respectively. The results for wheezing showed the Odd ratio for Age, gender, smoking, nationality and working duration were 1.02, 1.00, $0.44,2.55$ and 0.79 respectively. Reference groups are Females, non-smokers, Malaysian nationality, working $<=10$ years. Results presented with Odd ratio (OR) and 95\% Confidence Interval $(\mathrm{Cl})$. 
Malaysian Journal of Public Health Medicine 2020, Vol. 20 (3): 163-172

Table 3: The relationship between pulmonary function tests and selected risk factors

\begin{tabular}{|c|c|c|c|}
\hline \multirow{2}{*}{ Selected Risk Factors } & FEV $_{1}$ - predicted & FVC- predicted & PEFR- predicted \\
\hline & m (sd) & m (sd) & m (sd) \\
\hline \multicolumn{4}{|l|}{ Gender A } \\
\hline Male & $84.86(19.46)$ & $79.68(16.29)$ & $83.27(17.94)$ \\
\hline Female & $79.27(18.34)$ & $80.59(20.53)$ & 73.59 (17.28) \\
\hline $\mathrm{t}$ & 2.27 & -0.38 & 4.23 \\
\hline \multirow{2}{*}{\multicolumn{4}{|c|}{ Ethnicity B }} \\
\hline & & & \\
\hline Chinese & $87.80(18.45)$ & $84.52(18.77)$ & $85.39(17.49)$ \\
\hline Malay & $80.36(20.22)$ & 77.46 (18.70) & $76.69(16.47)$ \\
\hline Indian & $72.00(10.81)$ & $63.92(8.39)$ & $72.25(11.55)$ \\
\hline Others & $77.26(18.59)$ & $77.37(16.18)$ & $72.12(18.13)$ \\
\hline $\mathbf{F}$ & 6.66 & 6.69 & 10.12 \\
\hline p-value & $<0.001^{*}$ & $<0.001^{*}$ & $<0.001^{*}$ \\
\hline \multicolumn{4}{|l|}{ Nationality A } \\
\hline Malaysian & $86.03(18.68)$ & $82.72(18.51)$ & $84.11(17.05)$ \\
\hline Non-Malaysian & $77.21(18.69)$ & $76.23(17.15)$ & 71.79 (17.58) \\
\hline $\mathrm{t}$ & 3.61 & 2.76 & 5.46 \\
\hline \multirow{3}{*}{$\begin{array}{l}\text { p-value } \\
\text { Working Duration (hr/wk) } \\
\text { C } \\
\text { PFT m (sd) }\end{array}$} & $<0.001^{*}$ & $0.006^{*}$ & $<0.001^{*}$ \\
\hline & $59.31(20.29)$ & $59.31(20.29)$ & $59.31(20.29)$ \\
\hline & $82.44(19.18)$ & $80.07(18.21)$ & $89.24(12.49)$ \\
\hline$r$ & -0.012 & -0.06 & -0.133 \\
\hline p-value & 0.85 & 0.31 & $0.03^{*}$ \\
\hline \multicolumn{4}{|l|}{ Working Period A } \\
\hline$\leq 10$ years & $81.96(19.06)$ & $80.15(18.03)$ & $78.56(18.61)$ \\
\hline$>10$ years & 85.41 (19.68) & $79.59(19.56)$ & $82.35(15.84)$ \\
\hline$t$ & -0.97 & 0.16 & -1.12 \\
\hline $\mathrm{p}$-value & 0.33 & 0.86 & 0.26 \\
\hline \multicolumn{4}{|l|}{ Job Scope B } \\
\hline Chef & $82.74(17.02)$ & $79.36(16.85)$ & $79.83(17.18)$ \\
\hline Waiter & $80.28(19.51)$ & $81.25(22.67)$ & $74.50(19.98)$ \\
\hline Others & $84.80(22.05)$ & 79.69 (17.75) & $83.92(16.52)$ \\
\hline $\mathrm{F}$ & 0.963 & 0.25 & 4.78 \\
\hline p-value & 0.383 & 0.77 & $0.009^{*}$ \\
\hline \multicolumn{4}{|l|}{ Types of Restaurant B } \\
\hline Casual dining & $82.66(18.73)$ & $79.81(16.85)$ & $79.22(18.76)$ \\
\hline Cafe & $84.61(20.61)$ & $86.34(22.67)$ & $80.95(17.70)$ \\
\hline Othersmr & $82.44(19.15)$ & 74.69 (17.75) & $76.53(16.60)$ \\
\hline $\mathbf{F}$ & 0.78 & 3.93 & 0.55 \\
\hline p-value & 0.45 & $0.02^{*}$ & 0.57 \\
\hline
\end{tabular}

$\pi$ job scope others $=$ Admin, Cleaner, Barista or Rider, $\pi \pi$ Types of restaurants others $=$ Mamak, Café, Buffet or Fast Food. , independent samples $t$-test, $B$ ANOVA

C Pearson Correlation

Table 4: The binary logistic regression analysis for the respiratory symptoms and selected risk factors

\begin{tabular}{llll}
\hline Independent Variables & Chronic Cough & Breathlessness & Wheezing \\
\cline { 2 - 4 } & OR & OR & OR \\
& $95 \% \mathrm{Cl}$ & $95 \% \mathrm{Cl}$ & $95 \% \mathrm{Cl}$ \\
\hline Age & 1.04 & 0.98 & 1.02 \\
& $0.96-1.13$ & $0.96-1.01$ & $0.98-1.06$ \\
Gender & 1.72 & 1.60 & 1.00 \\
& $0.34-8.51$ & $0.80-3.19$ & $0.37-2.68$ \\
Smoking & 0.30 & 0.55 & 0.44 \\
Nationality & $0.065-1.46$ & $0.27-1.07$ & $0.18-1.12$ \\
\multirow{2}{*}{ Working Duration } & $12.21^{*}$ & 1.16 & $2.55^{*}$ \\
& $2.54-58.53$ & $0.66-2.04$ & $1.18-5.50$ \\
& 0.20 & 0.64 & 0.79 \\
\hline
\end{tabular}




\section{DISCUSSION}

\section{Respiratory symptoms}

According to the current study, the respiratory symptoms most complained by restaurant workers in Sungai Long was breathlessness and wheezing which accounted for $33.7 \%$ and $14.0 \%$ respectively. This result was in line with research conducted in Iran which recruited 60 kitchen workers and 60 unexposed employees to investigate the effect of cooking smoke to respiratory symptoms. Shortness of breath $(R R=$ $7.6 ; 95 \% \mathrm{Cl} 2.3,24.7)$, chest tightness $(\mathrm{RR}=6.2$; $95 \% \mathrm{Cl} 2.8,14.0)$ and wheezing $(\mathrm{RR}=4.8 ; 95 \% \mathrm{Cl}$ $1.3,17.8)$ was reported to be higher in kitchen workers than the control group; statistically significant ${ }^{10}$. On the other hand, the result of the current study was in contrast with research conducted among Mai Suyas', traditional barbecues workers in Nigeria. The study reported high prevalence of chest tightness $(\mathrm{OR}=3.1$; $95 \% \mathrm{Cl} 0.1,5.08)$, nasal congestion $(\mathrm{OR}=1.2$; $95 \% \mathrm{Cl} 1.04,1.89)$ and cough $(\mathrm{OR}=0.9 ; 95 \% \mathrm{Cl} 0.5$, 1.4). It is plausibly due to the difference in cooking method of the workers, whereby the cooking method of "Mai Suyas" produce more airborne impurities such as carbon monoxide, volatile organic compounds and carbonyl compounds ${ }^{11}$.

\section{Pulmonary function test}

The spirometry result for restaurant workers in Sungai Long were all within normal ranges except for PER which was slightly lower than the reference value of $80 \%{ }^{12}$. PEF that fell within the yellow zone indicated that the respiratory airway was getting narrowed and might in the need for extra treatment. As a comparison, most pulmonary function indices of restaurant workers in Sungai Long were lower than of that in Iran including the $\mathrm{FEV}_{1}(85.4 \%)$, FVC $(86.5 \%)$ and PEF $(89.9 \%)^{10}$.

\section{Respiratory Symptoms with Sociodemographic Factors}

Among the respiratory symptoms, risk factors found to be significantly associated with cough and wheezing were found in the ethnicities Javanese, Bamar, Bengali and country of origin particularly Indonesian, Burmese, Bangladeshis and South Indian. The significantly higher recorded prevalence of cough and wheezing among Non-Malaysians (foreign restaurant workers) could probably be explained to their poorer nutritional level and health status. Group of researchers have stressed that adequate intake of fruits, green vegetables and milk could help in improving lung functions as well as contribute to a decline in the prevalence of respiratory symptoms ${ }^{13}$.

Breathlessness was found to be significantly associated with age. Researchers proposed that despite conducting the same metabolic workload in both male and female, the older age group manifested greater breathlessness intensity as compared to the younger ones ${ }^{14}$. The study further explained the condition was the result of increased ventilatory mechanical restriction, reduced inspiratory muscle strength as well as increased demand for ventilation during exercise.

Respiratory symptoms with occupational characteristics

Table 2 showed the prevalence of cough was positively and significantly associated with the working duration (hours per week) of the restaurant workers. Longer working duration leads to prolonged exposure to airway irritants among the restaurant workers and hence increased the risk of developing respiratory symptoms. This statement is proven by a study conducted in Thailand which stated that the restaurant workers are more likely to develop "cough" by $15 \%$ with every extra 10 hours spent in the kitchen ${ }^{3}$.

\section{Pulmonary function test with sociodemographic factors}

The pulmonary structural difference between the two genders was always known to cause lower pulmonary function status in females. This was also shown in our study where females were significantly associated with lower $\mathrm{FEV}_{1}$ and PEF. This result was in line with research in the United State which claimed that hormonal influences and different pulmonary structures in females were the contributors to expiratory flow restriction, enhanced respiratory airway responsiveness and gas exchange disturbance ${ }^{15}$. The article was further supported by researchers who explained low pulmonary function status in females, was most probably due to smaller respiratory airway diameter relative to the size of the lung, lesser number of alveoli as well as smaller lung capacity in females ${ }^{16}$.

While for $\mathrm{FEV}_{1}$ and FVC, Indian was found to have significantly lowest values among other ethnicities. It could be explained by the anatomical discrepancy in Indians who are prone to have narrowed and shorter chest as well as lower expiratory and inspiratory muscle pressure ${ }^{17}$. Furthermore, the lower expiratory muscle strength would lead to earlier respiratory airway closure during exhalation ${ }^{18,19,20}$. In short, a combination of all these factors will lead to Indians have a smaller total lung capacity, thus poorer pulmonary function status.

\section{Pulmonary function test with occupational characteristics}

The findings of this study also showed that all pulmonary function test readings of restaurant workers were negatively correlated with working duration counted hours per week. However, only the correlation between working duration and PEF was statistically significant (Table 3 ). It was presumably due to prolonged exposure to kitchen irritants like cooking fumes as the result of long 
working duration. It was in congruence with a study that showed a significant association between exposures and reduction in $\mathrm{PEF}^{10,21}$.

\section{The predictors of the common respiratory symptoms}

The binary logistic regression showed the foreign workers are statistically significant predictors for the common respiratory symptoms among the restaurant workers in Sungai Long. Besides, the smokers showed lower odd ratio to develop respiratory symptoms as compared to nonsmokers, these results shed the light to the effect of working in a restaurant on the respiratory symptoms that overriding the effects of smoking on respiratory health ${ }^{18}$.

\section{Limitations}

The restaurants were selected randomly to avoid selection bias, and the study was carried out using a calibrated appliance to assess the pulmonary function status of the workers and validated standardized questionnaire to assess the respiratory health of the participants. The only unavoidable limitation was some of the foreign workers couldn't speak neither local nor English language and their colleagues have translated to them the researchers' questions.

\section{CONCLUSION}

It must be highlighted that studies on respiratory health of restaurant workers remains limited and were not much being investigated by researchers in this country, despite many similar studies conducted, published, and stressed by other foreign countries. Respiratory health of restaurant workers must not be overlooked as occupational lung diseases were the fourthhighest number of occupational diseases reported in the year 2018, according to the Department of Occupational Safety \& Health Malaysia19. This study demonstrated restaurant workers were at higher risk of developing respiratory symptoms and declined pulmonary function status, due to the frequent exposure towards hazardous elements released from cooking oil fumes inescapably, for instance, polycyclic aromatic hydrocarbons (PAH), formaldehyde, ketones etc that can potentially irritate the airway. Occupational characteristic was also found to be a probable factor associated with reducing respiratory health among restaurant workers. In general, this study showed that Indian restaurant workers as compared to other ethnic groups; female as compared to male and aged workers, had a lower pulmonary function status. Thus, this denotes a rising need to highlight proper preventive measure to ensure the well-being of them, with the establishment of law and effective guidelines to tackle this alarming issue.

\section{ACKNOWLEDGEMENTS}

We are immensely grateful to Universiti Tunku Abdul Rahman for funding this research. the research would not have been possible without their exceptional support.

\section{REFERENCES}

1. World Health Organisation. WHO releases country estimates on air pollution exposure and health impact. WHO 2016. [online] Available at: https: / /www. who.int/newsroom/detail/27-09-2016-who-releasescountry-estimates-on-air-pollutionexposure-and-health-impact (accessed 16 June 2019).

2. Lai C H, Jaakkola J K, Chuang C Y, et al. Longitudinal Study in Chinese Military Cooks. J Expo Sci Environ Epi 214; 23(1): pp.94-100.

3. Juntarawijit $\mathrm{C}$ and Juntarawijit $\mathrm{Y}$. Cooking smoke and respiratory symptoms of restaurant workers in Thailand. BMC Pulmonary Medicine 2017; 17(1). Available at: https: / /doi.org/10.1186/s12890-0170385-7 (accessed 5 Jun 2019).

4. Department of Occupational Safety and Health. Indoor Air Quality. DOSH 2019 [online] Available at: http: / /www.dosh.gov.my/index.php/en/ chemical-management/indoor-air-quality (Accessed 17 June 2019).

5. Department of Occupational Safety \& Health Malaysia. Occupational Diseases and Poisoning Investigation Until September 2018. DOSH 2018. [online] Available at: http://www.dosh.gov.my/index.php/en/ occupational-diseases- and-poisoningstatistic/2038-occupational-diseasesand-poisoning-investigation-untilseptember-2018 (accessed 15 Jun 2019).

6. Zatil Husna Wan Fauzi. Bandar Sungai Long spilling over | The Edge Markets 2015:

https: / / www.theedgemarkets.com/articl e/bandar-sungai-long-spilling-over (accessed 16 Jun 2019).

7. Medical Research Council. Medical Research Council Questionnaire on Respiratory Symptoms (1986).

https://mrc.ukri.org/documents/pdf/qu estionnaire-on-respiratory-symptoms1986/ (accessed 16 June 2019).

8. Medical International Research. Spirobank II.

https: / /www.spirometry.com/ENG/Prod 
ucts/spirobank2.asp (accessed 16 June 2019).

9. Clement Clarke International Ltd. Peak flow meter MINI-WRIGHT STANDARD. https: / /www.medicalexpo.com/request/ form.html?token=1R3RagWDvGZ884BGdP mpkVDH1bQA5xfyluiDr78dF9nt9v5yCW03 ZUsxsI3g7Z63k1auPDiSXkEgNiHWncZb3JW aNZh14iQdYHDHUSxFvAq04gk7zlbmeKtPA 6bGCcRLBMOEPNcvLV4hmRNQrC2l10ZVen wF1JrxH7BdSXreQCPHw04tY0iG0Jh5V6db bBKTiogi2Pn1UwVtkm46FFj9Zhcej (accessed 26 July 2020).

10. Neghab M, Delikhoon M, Baghani A N and Hassanzadeh J. Exposure to Cooking Fumes and Acute Reversible Decrement in Lung Functional Capacity. Int J Occup Environ Med 2017 8(4): 207-216.

11. Adewole O, Desalu O, Nwogu K C et al. Respiratory Symptoms and Lung Function Patterns in Workers Exposed to Wood Smoke and Cooking Oil Fumes (Mai Suya) in Nigeria. Ann of Med and Health Sci Res 2013; 3(1): 38-42.

12. American Lung Association. Lung Health \& Diseases. [online]. Available at: https: / / www.lung.org/lung-health-anddiseases/lung-diseaselookup/asthma/living-withasthma/managing-asthma/measuringyour-peak-flow-rate.html (accessed 16 September 2019).

13. He, Q.Q., Wong, T.W., Du, L., Lin, G.Z., Gao, Y., Jiang, Z.Q., Yu, T.I., Wu, J.G., Lin, L. and Lin, R., 2008. Nutrition and children's respiratory health in Guangzhou, China. Public Health 2008; 122 (12):1425-1432.

14. Ofir D, Laveneziana P, Webb K, et al. Sex differences in the perceived intensity of breathlessness during exercise with advancing age. J of App Physio 208; 104(6):1583-1593.

15. Harms C and Rosenkranz S. Sex differences in pulmonary function during exercise. Medicine and Science in Sports and Exercise 2008;40(4):664-668.

16. Guenette J, Witt J, McKenzie D et al. Respiratory mechanics during exercise in endurance-trained men and women. The $\mathrm{J}$ of physio 2007; 581(Pt 3):1309-22.

17. Donnelly P, Yang T, Peat J and Woolcock A. What factors explain racial differences in lung volumes? Europ Resp J 1991; 4(7):829-838.
18. Yang $\mathrm{T}$, Peat $\mathrm{J}$, Keena $\mathrm{V}$ et al. A review of the racial differences in the lung function of normal Caucasian, Chinese and Indian subjects. Europ Resp J 1991; 4(7):872880.

19. Department of Occupational Safety \& Health Malaysia. Occupational Diseases and Poisoning Investigation Until September 2018. [online] Available at: http: / / www.dosh.gov.my/index.php/en/ occupational-diseases-and-poisoningstatistic/2038-occupational-diseasesand-poisoning-investigation-untilseptember-2018 (accessed 15 Jun. 2019).

20. Shaik Farid Aw, Ahmad Rasdan Ismail and Rohayu 0 . How workplace condition affects health workers: assessment at tertiary hospitals. Malaysian J Public Health and Medicine 2020; Sp 1: 251-254.

21. Mohd Hidayat Ab Rahman, Nurul Ain Maidin, Umi Hayati Ahmad, Mohd Salahuddin Mohd Basri, Mohd Nazri Ahmad, Ridhwan Jumaidin, Mohd Hairizal Osman and Mohamad Khalid Wahid. Malaysian J Public Health and Medicine 2020; Sp 1: 138-144. 